\title{
Association of Tooth Loss with Systemic Health of Saudi Population residing in Al-Qassim Region- a Retrospective Study
}

Fayza Rashed Albluwe*

Dentist, Qassim Regional Dental Center, Qassim, Saudi Arabia

DOI: $10.36348 /$ sjodr.2020.v05i08.004 | Received: 01.08.2020 | Accepted: 08.08.2020 | Published: 13.08 .2020

*Corresponding author: Fayza Rashed Albluwe

\section{Abstract}

Objective: The purpose of the study to assess the relationship between oral health and the general health of individuals especially tooth loss and the systemic illness. Materials and Methods: A retrospective study of 804 digital orthopantomograms (OPGS) taken of patients, age ranging between 20 and 70 years, who presented to treatment at the Regional Dental Center, AL-Qassim, Saudi Arabia between 2018 and 2019. The OPGS and dental records were reviewed for missing teeth among patients with systemic illness. Results: We found a high prevalence of tooth loss in hypertension (10.63), DM (9.62), hypothyroidism (6.79) and Asthma (6.35). Conclusion: This study reported a high prevalence of tooth loss among the patients with systemic illness rather than the patients with no systemic illness. The presence of more than one illness and older age patients showed a high prevalence of tooth loss. These findings clarify the importance of the effect of the systemic health on the oral health.

Keywords: tooth loss, systemic illness, oral health Saudi.

Copyright @ 2020: This is an open-access article distributed under the terms of the Creative Commons Attribution license which permits unrestricted use, distribution, and reproduction in any medium for non-commercial use (NonCommercial, or CC-BY-NC) provided the original author and source are credited.

\section{INTRODUCTION}

Tooth loss is one of the most prevalent oral conditions and ranks as one of the hundred adverse health conditions that affect the population of the world. Among all oral conditions, tooth loss is also the leading cause of disability-adjusted life years (DALYs) accounting for 7.6 million DALYs. Untreated caries affects 2.5 billion people in the world and is considered as the most common Global Burden of Diseases (GBD) worldwide [1]. This is a cause for concern as caries and periodontal disease are also the most common prequels of tooth loss in adults [2]. A study conducted in 2014 reported that $2.3 \%$ of the world's population around 158 million people was edentulous. The study also reported that even though the global prevalence of agestandardized for tooth loss has decreased from $4.4 \%$ to $2.4 \%$ from 1990 to 2010 , which presented as $45 \%$ reduction in the number of the entire population. The limited reports from the developed countries which directly make possible attempts to correctly quantify tooth loss are difficult and very limited data become typically emerged from the developing world [3]. Although conservation is the predominant philosophy in dental education and practice, it is often unavoidable to remove teeth due to the time-dependent progression of oral diseases that increase the likelihood of tooth loss during adulthood [3, 4]. It is incessantly not only a debilitating condition in used terms of personal function and esthetics but also has a psychological impact and adversely affects the personal quality of life $[5,6]$.

Oral diseases that lead to tooth loss like periodontitis and caries provide well-established links with the systemic health of individuals. Enough evidence reports the possible association of periodontitis with cardiovascular disorders [7], diabetes mellitus (DM) [8, 9], and other systemic conditions [1013]. Tooth loss itself has been attributed as a comorbidity risk factor for many systemic diseases and the number of teeth present in the mouth has been identified as a reliable predictor of disease-specific mortality. For example, a prospective study conducted over 12 years on a large cohort of 7,674 subjects reported a direct correlation between the number of teeth and cardiovascular disease mortality [14]. Another study conducted on a large Chinese population reported the association of tooth loss with increased risk of death from upper gastrointestinal cancer, heart disease, and stroke [15]. Similarly, a long-term prospective study done in Japan tried to examine the relationship between functional teeth numbers in the mouth and 15-year mortality in the sample. The study reported a significantly higher mortality rate in people who had 10 or less than 10 functional teeth [16]. Another long term 
prospective study done on 48,375 male participants in the US with a median follow up of 17.7 years reported that fewer teeth in the mouth were associated with an increased risk of lung cancer [17]. These studies simply indicate there is an association between tooth loss and the systemic health of an individual.

Tooth loss is a problem that has also affected the Saudi population but studies assessing the prevalence of tooth loss in adults are very rare. A fiveyear survey conducted by Shinawi in 2012 on patients in Jeddah, Saudi Arabia did not shed light on the prevalence of tooth loss as much as it did on the pattern although it did report that the most common type of tooth loss pattern was partial edentulous with Kennedy's Class III being the most common of them in both genders and both arches [28]. The most important study that attempts to present tooth loss prevalence in adults was conducted in 2017 in the city of Dammam. This study reported that out of 479 participants aged above 25 years, $74 \%$ were partially edentulous, $6 \%$ were completely edentulous, $8 \%$ had one edentulous arch and $12 \%$ had no missing teeth. This study reported correlations of tooth loss with systemic disorders e.g DM and heart diseases as well as with smoking [18]. However, studies involving large samples that sufficiently establish a direct correlation of tooth loss with systemic disorders in the Saudi population do not exist. Our present research aims to evaluate the used effect of general health on oral health and the possible association between tooth loss and systemic health in Al-Qassim Region, Saudi Arabia.

\section{MATERIALS AND METHODS}

The present study is a retrospective study conducted in the Al-Qassim Regional Center in AlQassim, Saudi Arabia. Ethical approval for the study was obtained from the Institutional Review Board
(Regional research Ethics committee, Registered at the National Committee of Bio, Med Ethics (NCBE) with IRB no. H-04-Q-001.The sample in this study consisted of patient records that included 804 digital Orthopantomograms (OPGs) and files stored in the Care Stream R4 Clinical and Practice Management Database (the filing software used by the center). The Inclusion criteria included the files of patients aged between 20-70 years and Only OPG and files from 2018 to 2019 were selected. The exclusion criteria files those are incomplete. The Patients were divided into groups based on age and number of missing teeth. Data were analyzed comparing the number of missing teeth and gender and whether they were systemically healthy or not. Data were coded and entered into a spreadsheet using Microsoft Excel 16.0. Descriptive statistics were used to obtain the frequency distribution of data. Inferential analysis was performed using Statistical Package for Social Sciences (SPSS, IBM Version 22.0). Student's t-tests and one-way ANOVA were used to compare the means and establish an association between variables. All p values below an alpha level of 0.05 at $95 \%$ confidence interval (CI) were considered statistically significant.

\section{RESULTS}

A total of 804 were records met the inclusion criteria and were reviewed. Table 1 shows us the distribution of the patients by age, gender, systemic health, and number of missing teeth. The majority of the patients were $(29.5 \%)$ of age group $20-30$ followed by the age group of more than 50 years $(28.5 \%)$. More than half $(57.1 \%)$ of patients were females while $(42.9 \%)$ were males and half of them $(50 \%)$ had a systemic illness compared to $50 \%$ without systemic illness. The majority of the patients $(72.4 \%)$ had 1 to 10 missing teeth (mean $6 \pm 6$ ).

Table-1: Patients characteristics (age, gender, systemic health, and number of missing teeth) $(\mathrm{N}=804)$

\begin{tabular}{|c|c|c|c|}
\hline \multicolumn{2}{|r|}{ Category } & No & $\%$ \\
\hline \multirow[t]{4}{*}{ Age } & $20-30$ years & 237 & $29.5 \%$ \\
\hline & $31-40$ years & 179 & $22.3 \%$ \\
\hline & $41-50$ years & 159 & $19.8 \%$ \\
\hline & more than 50 years & 229 & $28.5 \%$ \\
\hline \multirow[t]{2}{*}{ Gender } & Female & 459 & $57.1 \%$ \\
\hline & Male & 345 & $42.9 \%$ \\
\hline \multirow{2}{*}{$\begin{array}{l}\text { systemic } \\
\text { illness }\end{array}$} & No & 402 & $50.0 \%$ \\
\hline & Yes & 402 & $50.0 \%$ \\
\hline \multirow{4}{*}{$\begin{array}{l}\text { Number of } \\
\text { missing teeth }\end{array}$} & No missing teeth & 106 & $13.2 \%$ \\
\hline & 1 - 10 teeth's & 582 & $72.4 \%$ \\
\hline & $11-20$ teeth's & 85 & $10.6 \%$ \\
\hline & $21-32$ teeth's & 31 & $3.9 \%$ \\
\hline
\end{tabular}


Fayza Rashed Albluwe; Saudi J Oral Dent Res, August, 2020; 5(8): 373-378

Table2: Show us the distribution of different patients systemic illness from the overall sample $(\mathrm{n}=804)$. DM was the most common disorder found in patients with systemic illness $(22.1 \%)$ followed by hypertension $(16.3 \%)$, other systemic illness (12.4\%), hypothyroidism $(8.8 \%)$ asthma $(7.5 \%)$ heart disorders, elevated cholesterol, liver/kidney diseases and hyperthyroidism $(4.2 \%, 1.7 \%, 1.2 \%$, and $0.6 \%$ respectively).

Table-2: Show us the distribution of different patients systemic illness from the overall sample $(\mathrm{n}=804)$

\begin{tabular}{|l|l|l|l|}
\hline \multirow{2}{*}{ Variable } & \multicolumn{2}{|c|}{} \\
\cline { 2 - 4 } & Number & $\%$ \\
\hline \multirow{2}{*}{ Cholesterol } & no & 388 & $48.3 \%$ \\
\cline { 2 - 4 } & Yes & 14 & $1.7 \%$ \\
\hline \multirow{2}{*}{ DM } & no & 224 & $27.9 \%$ \\
\cline { 2 - 4 } & yes & 178 & $22.1 \%$ \\
\hline \multirow{2}{*}{ Hypertension } & no & 271 & $33.7 \%$ \\
\cline { 2 - 4 } & yes & 131 & $16.3 \%$ \\
\hline \multirow{2}{*}{ Asthma } & no & 342 & $42.5 \%$ \\
\cline { 2 - 4 } & yes & 60 & $7.5 \%$ \\
\hline \multirow{2}{*}{ Heart disorder } & no & 368 & $45.8 \%$ \\
\cline { 2 - 4 } & yes & 34 & $4.2 \%$ \\
\hline \multirow{2}{*}{ Hyperthyroidism } & no & 397 & $49.4 \%$ \\
\cline { 2 - 4 } & yes & 5 & $0.6 \%$ \\
\hline \multirow{2}{*}{ Liver and kidney disease } & no & 392 & $48.8 \%$ \\
\cline { 2 - 4 } & yes & 10 & $1.2 \%$ \\
\hline \multirow{2}{*}{ Hypothyroidism } & no & 331 & $41.2 \%$ \\
\cline { 2 - 4 } & yes & 71 & $8.8 \%$ \\
\hline \multirow{2}{*}{ Others, not specified systemic illness } & no & 302 & $37.6 \%$ \\
\cline { 2 - 4 } & yes & 100 & $12.4 \%$ \\
\hline
\end{tabular}

Table 3: show us Patients with more than one systemic illness had a greater number of missing teeth (mean $8.51 \pm 6.61$ ) than compared to $6.31 \pm 5.53$ patients who have only one systemic illness which was statistically significant.

Table-3: Relationship between number of missing teeth and patient who have one systemic illness and others who have more than one systemic illness $(\mathrm{N}=\mathbf{4 0 2})$

\begin{tabular}{|l|l|l|l|l|c|c|}
\hline \multicolumn{2}{|l|}{ Nature of medical disordered patients } & N & Mean & Std. Deviation & t-value & Sig. \\
\hline \multirow{2}{*}{ Number of missing teeth } & Only one systemic illness & 51 & 6.31 & 5.533 & $-2.262-$ & .024 \\
\cline { 2 - 5 } & More than one systemic illness & 351 & 8.51 & 6.605 & & \\
\hline
\end{tabular}
t-test, P-value significant at .05 level

Table4: show us Statistical significance was seen in the number of missing teeth in patients with systemic illness at $(\mathrm{p}=0)$, where the mean number of missing teeth in patients with systemic illness were higher (i.e. 8.23 compared to 3.34 ) in patients without systemic illness.

Table-4: Mean number of missing teeth of patients with systemic illness or not $(\mathbf{N}=804)$

\begin{tabular}{|l|l|l|l|l|c|}
\hline & Systemic illness & N & Mean & t-value & Sig. \\
\hline \multirow{2}{*}{ Number of missing teeth } & No & 402 & 3.34 & $-12.763-$ & .000 \\
\cline { 2 - 4 } & Yes & 402 & 8.23 & & \\
\hline
\end{tabular}

t-test, P-value significant at .05 level

The association of the number of missing teeth with different systemic illness is illustrated in Table 5. The results showed that type of patients with systemic illness who suffered from DM, hypertension, asthma, and hypothyroidism had a higher number of missing teeth than compared to patients without those illnesses at $(\mathrm{P}$-value $\geq 0.05)$. 
Fayza Rashed Albluwe; Saudi J Oral Dent Res, August, 2020; 5(8): 373-378

Table-5: The relationship between the number of missing teeth and the different type of systemic illness

\begin{tabular}{|l|l|l|l|}
\hline \multirow{2}{*}{ Number of missing teeth } & \multicolumn{2}{|c|}{} \\
\cline { 2 - 4 } & Mean & t-value & Sig \\
\hline Cholesterol & 7.86 & .219 & .827 \\
\hline DM & 9.62 & $-3.871-$ & .000 \\
\hline Hypertension & 10.63 & $-5.313-$ & .000 \\
\hline Asthma & 6.35 & 2.441 & .015 \\
\hline Heart disorders & 9.26 & $-.967-$ & .334 \\
\hline Hyperthyroidism & 7.00 & .425 & .671 \\
\hline liver and kidney disease & 8.70 & $-.230-$ & .818 \\
\hline Hypothyroidism & 6.79 & 2.065 & .040 \\
\hline Others not specified illness & 8.83 & $-1.061-$ & .290 \\
\hline
\end{tabular}

t-test, P-value significant at .05 level

Table6: The correlation between number missing teeth and different age groups is illustrated in table 6 which is statistically significant $(\mathrm{p} \leq 0.05)$. These results indicate that older patients had more missing teeth, with patients more than 50 years old having the highest number of missing teeth; mean $=$ $10.71 \pm 7.31$ than compared to $6.33 \pm 4.68$ for 41 to 50 years, $4.21 \pm 3.28$ for 31 to 40 years and lowest mean for 20 to 30 years of age (mean $1.85 \pm 2.29$ ).

Table-6: Relationship between number missing teeth and different age groups

\begin{tabular}{|c|c|c|c|c|c|}
\hline Age groups ad number of missing teeth & No & Mean & Std. Deviation & $\mathbf{F}$ & Sig. \\
\hline 20 - 30 years & 237 & $1.85^{\mathrm{b}, \mathrm{c}, \mathrm{d}}$ & 2.296 & \multirow[t]{4}{*}{137.483} & \multirow[t]{4}{*}{.000} \\
\hline $31-40$ years & 179 & $4.21^{\mathrm{a}, \mathrm{c}, \mathrm{d}}$ & 3.287 & & \\
\hline $41-50$ years & 159 & $6.33^{\mathrm{a}, \mathrm{b}, \mathrm{d}}$ & 4.682 & & \\
\hline more than 50 years & 229 & $10.71^{\mathrm{a}, \mathrm{b}, \mathrm{c}}$ & 7.314 & & \\
\hline
\end{tabular}

ANOVA test, P-value significant at .05 level

\section{DISCUSSION}

Systemic health stands as one of the most important aspect for the population of the whole world. The systemic health of individuals is considered as a priority by each dental and medical staff during their procedures. There seems to be an association between systemic health and oral health as supported by different studies [10-13]. The different types of systemic health conditions have been associated between missing teeth and periodontal disease in the literature. Poor oral health has also shown to have a clear effect on the systemic health of individuals [19].

To the best of the readers' knowledge, this research is the first of a kind in Saudi Arabia that studies a large sample to examine the associations of tooth loss with the systemic health of patients. These types of studies are important because trends in results that are presented as associations indicate risk factors for systemic conditions. This means that loss of teeth in patients can indicate to the dental practitioner that there might be an underlying systemic condition that the patient is not aware of and the dental practitioner can recommend appropriate referrals. Conversely, some systemic conditions can be considered as early indicators of periodontal diseases in the patients and general physicians can recommend dental examinations for patients who have DM, cardiovascular and pulmonary diseases as well as other diseases associated with increased risk of tooth loss [10-13] and this can help prevent tooth loss by early initiation of conservative therapies. Our research presents some important trends in tooth loss among the Saudi population. Even though $50 \%$ of the sample was healthy, $86.9 \%$ of them had missing teeth. This is similar to another study conducted in Dammam where $88 \%$ of the sample had missing teeth. However, that study did not include healthy participants [19]. The NCHS data brief of 2015 presented tooth loss trends among adults in the United States. The report stated that $52 \%$ of the sample had missing teeth which is much less than our sample [20]. Similarly, another study conducted in the US reported missing teeth in only $42.4 \%$ of the sample [21]. A prospective study from Brazil reported a higher prevalence of tooth loss in $67.8 \%$ of the sample at baseline with a further $12.5 \%$ during follow-up [22]. Most of the patients (72.4\%) had 1-10 missing teeth. This is almost similar to the study done in Dammam where $78.81 \%$ of participants had 110 missing teeth. DM was the most common disorder found in this study but other studies have varied reports on the most prevalent systemic conditions among patients with tooth loss.

A study conducted by Hamasha et al. in 2018 reports hypertension to be the most common condition among the sample [23]. The same study reported the mean number of 5.8 missing teeth per person as compared to the mean number of missing teeth in our study which was $8.3 \pm 6.51$ in patients with systemic illness and $3.34 \pm 4.08$ in patients without systemic illness. Furthermore, a statistically significant 
difference existed in the presence of missing teeth in individuals who had hypertension $(\mathrm{p}=0), \mathrm{DM}(\mathrm{p}=0)$, asthma $(\mathrm{p}=0.015)$, and hypothyroidism $(\mathrm{p}=0.04)$. The number of missing teeth was also associated with the presence of more than one systemic illness $(8.51 \pm 6.61$ compared to $6.31 \pm 5.53$ ) for those who have only one systemic illness. This can be best explained by the fact that the presence of multiple illnesses in individuals can have a compounding effect on the risks for tooth loss as proven by several studies $[7,15,16]$. Tooth loss also had a significant association with age in this study. The group that had the highest mean number of missing teeth was the most elderly i.e. above 50 years (mean = 10.71 7.31 ). This is confirmed by another study by AlShammery et al. (1998) where the group having the highest mean number of lost teeth was the most elderly group aged $65-74$ years $($ mean $=15.79)$ [24]. There are several reasons why an advanced age can be associated with increased tooth loss. Issues with a dexterity that prevent proper brushing [25], increased incidence of dental diseases in advanced age [26] as well as barriers to access dental services [27] could be some of the reasons. Gender was not significantly associated with missing teeth in our study although other studies have reported the association of gender with missing teeth $[18,22]$.

\section{CONCLUSION}

The number of missing teeth in systemic illness patients was higher than in patients without systemic illness. The highest number of missing teeth was found in individuals with hypertension, DM, hypothyroidism and Asthma .The old aged individuals had more missing teeth than younger individuals. The gender of the individual didn't have any influence on the number of missing teeth either in patients with systemic illness or in patients without systemic illness. These findings clarify the importance of the effect of the systemic health on the oral health.

\section{ACKNOWLEDGMENT}

Author Would like to Thank Dr. Saad Al-harbi Consultant of Endodontic and Administrator of Qassim Regional Dental Center for his Encouragement and Positive Words when the author Suggested Research Topic for him, Also Author would like to thanks Dr. Mohammed Nabil Specialist of maxillofacial Surgery, Medical Director of Qassim Regional Dental center, Dr. Jasmine Ismail Specialist of maxillofacial Surgery, Dr.Enas Abusamra specialist of Endodontic, and Dr.shebin Ibrahim consultant of prosthodontics for their Encouragement.

\section{REFERENCES}

1. Kassebaum, N. J., Smith, A. G. C., Bernabé, E., Fleming, T. D., Reynolds, A. E., Vos, T., ... \& GBD 2015 Oral Health Collaborators. (2017). Global, regional, and national prevalence, incidence, and disability-adjusted life years for oral conditions for 195 countries, 1990-2015: a systematic analysis for the global burden of diseases, injuries, and risk factors. Journal of dental research, 96(4), 380-387.

2. Petersen, P. E. (2003). The World Oral Health Report 2003: continuous improvement of oral health in the 21st century - the approach of the WHO Global Oral Health Programme. Community Dent Oral Epidemiol, 31(1):3-24.

3. Kassebaum, N. J., Bernabé, E., Dahiya, M., Bhandari, B., Murray, C. J. L., \& Marcenes, W. (2014). Global burden of severe tooth loss: a systematic review and meta-analysis. Journal of dental research, 93(7_suppl), 20S-28S.

4. Müller, F., Naharro, M., \& Carlsson, G. E. (2007). What are the prevalence and incidence of tooth loss in the adult and elderly population in Europe?. Clinical oral implants research, 18, 2-14.

5. Gerritsen, A. E., Allen, P. F., Witter, D. J., Bronkhorst, E. M., \& Creugers, N. H. (2010). Tooth loss and oral health-related quality of life: a systematic review and meta-analysis. Health and quality of life outcomes, 8(1), 126.

6. Gerritsen, A. E., Allen, P. F., Witter, D. J., Bronkhorst, E. M., \& Creugers, N. H. (2010). Tooth loss and oral health-related quality of life: a systematic review and meta-analysis. Health and quality of life outcomes, 8(1), 126.

7. Janket, S. J., Baird, A. E., Chuang, S. K., \& Jones, J. A. (2003). Meta-analysis of periodontal disease and risk of coronary heart disease and stroke. Oral Surgery, Oral Medicine, Oral Pathology, Oral Radiology, and Endodontology, 95(5), 559-569.

8. Casanova, L., Hughes, F. J., \& Preshaw, P. M. (2014). Diabetes and periodontal disease: a twoway relationship. British dental journal, 217(8), 433-437.

9. Chávarry, N. G. M., Vettore, M. V., Sansone, C., \& Sheiham, A. (2009). The relationship between diabetes mellitus and destructive periodontal disease: a meta-analysis. Oral health \& preventive dentistry, 7(2).

10. Chaffee, B. W., \& Weston, S. J. (2010). Association between chronic periodontal disease and obesity: a systematic review and metaanalysis. Journal of periodontology, 81(12), 17081724.

11. Polyzos, N. P., Polyzos, I. P., Mauri, D., Tzioras, S., Tsappi, M., Cortinovis, I., \& Casazza, G. (2009). Effect of periodontal disease treatment during pregnancy on preterm birth incidence: a metaanalysis of randomized trials. American journal of obstetrics and gynecology, 200(3), 225232.

12. Detert, J., Pischon, N., Burmester, G. R., \& Buttgereit, F. (2010). The association between rheumatoid arthritis and periodontal disease. Arthritis research \& therapy, 12(5), 218.

13. Han, K., Hwang, E., \& Park, J. B. (2016). Association between consumption of coffee and the 
prevalence of periodontitis: the 2008-2010 Korea National Health and Nutrition Examination Survey. PloS one, 11(7), e0158845.

14. Holmlund, A., Holm, G., \& Lind, L. (2010). Number of teeth as a predictor of cardiovascular mortality in a cohort of 7,674 subjects followed for 12 years. Journal of periodontology, 81(6), 870876.

15. Abnet, C. C., Qiao, Y. L., Dawsey, S. M., Dong, Z. W., Taylor, P. R., \& Mark, S. D. (2005). Tooth loss is associated with increased risk of total death and death from upper gastrointestinal cancer, heart disease, and stroke in a Chinese population-based cohort. International journal of epidemiology, 34(2), 467-474.

16. Fukai, K., Takiguchi, T., Ando, Y., Aoyama, H., Miyakawa, Y., Ito, G., ... \& Sasaki, H. (2007). Functional tooth number and 15- year mortality in a cohort of community- residing older people. Geriatrics \& gerontology international, 7(4), 341-347.

17. Michaud, D. S., Liu, Y., Meyer, M., Giovannucci, E., \& Joshipura, K. (2008). Periodontal disease, tooth loss, and cancer risk in male health professionals: a prospective cohort study. The lancet oncology, 9(6), 550-558.

18. Fouda, S. M., Al-Harbi, F. A., Khan, S. Q., Virtanen, J. I., \& Raustia, A. (2017). Missing teeth and prosthetic treatment in patients treated at College of Dentistry, University of Dammam. International Journal of Dentistry, 2017.

19. Alpert, P. T. (2017). Oral health: the oral-systemic health connection. Home Health Care Management \& Practice, 29(1), 56-59.

20. Dye, B. A., Thornton-Evans, G., Li, X., \& Iafolla, T. (2015). Dental caries and tooth loss in adults in the United States, 2011-2012. US Department of
Health and Human Services, Centers for Disease Control and Prevention, National Center for Health Statistics.

21. Jiang, Y., Okoro, C. A., Oh, J., \& Fuller, D. L. (2013). Peer reviewed: sociodemographic and health-related risk factors associated with tooth loss among adults in Rhode Island. Preventing chronic disease, 10.

22. De Marchi, R. J., Hilgert, J. B., Hugo, F. N., Santos, C. M. D., Martins, A. B., \& Padilha, D. M. (2012). Four- year incidence and predictors of tooth loss among older adults in a southern B razilian city. Community Dentistry and Oral Epidemiology, 40(5), 396-405.

23. Hamashaa, A. A. H., Almogbela, L., Alshehria, A., Alssafia, F., Alghamdia, H., Alajmia, A., \& Rajionc, Z. A. (2018). Medical conditions associated with tooth loss among Saudi adults. Archives of Orofacial Science, 13(1), 16-21.

24. Guile, E. E. (1998). Permanent tooth loss among adults and children in Saudi Arabia. Community dental health, 15(4), 277-280.

25. Worthington, H., Clarkson, J., \& Davies, R. (1999). Extraction of teeth over 5 years in regularly attending adults. Community dentistry and oral epidemiology, 27(3), 187-194.

26. Ettinger, R. L. (1993). Cohort differences among aging populations: a challenge for the dental profession. Special Care in Dentistry, 13(1), 19-26.

27. Kiyak, H. A., \& Reichmuth, M. (2005). Barriers to and enablers of older adults' use of dental services. Journal of dental education, 69(9), 975986.

28. Shinawi, L. A. (2012). Partial edentulism: a five year survey on the prevalence and pattern of tooth loss in a sample of patients attending King AbdulAziz University-Faculty of Dentistry. Life Science Journal, 9(4), 2665-2671. 